\title{
Física com Martins e Eu: Recordações da história e da obra de Pierre Lucie (1917-2017)
}

\author{
Physics with Martins and Me: Memories of the History and Work of Pierre Lucie (1917-2017) \\ Evaldo Victor Lima Bezerra*1 \\ ${ }^{1}$ Centro Universitário Campos Andrade, Curitiba, PR, Brasil
}

Recebido em 24 de March, 2017. Revisado em 02 de May, 2017. Aceito em 08 de May, 2017

\begin{abstract}
No dia 31 de maio de 1946, desembarcou no porto do Rio de Janeiro um jovem engenheiro francês chamado Pierre Henri Lucie, vindo de uma Europa arrasada pela guerra, em busca de uma vida melhor. Após um início modesto como caminhoneiro e montador de rádios, foi descoberto por outros compatriotas que o convidaram para lecionar matemática e física em colégios e cursos preparatórios para vestibular. Nos primeiros anos de docência Pierre começou a destacar-se, desenvolvendo uma didática e um amor pelo magistério que ainda hoje são difíceis de encontrar. Participou de muitos projetos e propostas para a melhoria do ensino de física, em especial, Física com Martins e Eu, seu livro didático para o ensino médio, escrito no final de 1969 e inicio de 1970. O livro nasceu de uma brincadeira com o cartunista Henrique de Souza Filho (Henfil), o gibi da física. Este trabalho é uma singela homenagem a memória desse importante educador no ano do centenário de seu nascimento, também uma oportunidade para analisar seu livro. Física com Martins e Eu surpreende por sua postura de vanguarda. Muitos critérios exigidos hoje em dia pelo Programa Nacional do Livro Didático (PNLD) e por outras legislações para o ensino médio aparecem em suas páginas. O livro é recheado pelo gênero textual história em quadrinhos, além de um texto muito bem escrito que busca um diálogo constante com o leitor, convidando-o a reflexão e a experimentação.
\end{abstract}

Palavras-chave: História da Ciência, Livro Didático, Pierre Lucie.

\begin{abstract}
On May 31, 1946, a young French engineer named Pierre Henri Lucie landed in the port of Rio de Janeiro from a war-torn Europe in search of a better life. After a modest start as a truck driver and assembler of radios, he was discovered by other compatriots who invited him to teach mathematics and physics in colleges and preparatory courses for college entrance exams. In the first years of teaching Pierre began to excel, developing a didactic and a love for teaching that are still difficult to find today. He participated in many projects and proposals for the improvement of physics teaching, especially Physics with Martins and Me, his textbook for high school, written in late 1969 and early 1970. The book was born of a joke with the cartoonist Henrique de Souza Filho (Henfil), the comic book of physics. This work is a simple tribute to the memory of this important educator in the centenary year of his birth, also an opportunity to analyze his book. Physics with Martins and Me surprises by its avant-garde stance. Many criteria demanded today by the National Textbook Program (PNLD) and other legislations for high school appear on its pages. The book is filled with textual genre comics, as well as a very well written text that seeks a constant dialogue with the reader, inviting him to reflection and experimentation.
\end{abstract}

Keywords: History of Science, Didactic Book, Pierre Lucie.

\section{Biografia}

Nossa história tem início numa pequena cidade da Gasconha chamada Condom, situada no sudoeste da França, foi ali que em 14 de agosto de 1917 nasceu Pierre Henri Lucie (figura 1). Filho do comerciante Henri Joseph Lucie e de Françoise Henriette Bouteille, Pierre teve uma infância tranquila e modesta, mesmo vivendo num período entre guerras.

Na juventude ele ingressou na faculdade de ciências de Toulouse, cidade mais ao sul a aproximadamente $100 \mathrm{~km}$ de distância de Condom. Lá ele conheceu o seu

*Endereço de correspondência: evaldo.bezerra@uniandrade.edu.br grande mestre, o físico Henri Bouasse ${ }^{1}$ (1866-1953) que imprimiu em Pierre um forte desejo para o ensino de física. Bouasse (figura 2) tinha vocação para o ensino e um grande compromisso ao trabalhar em projetos de reforma do ensino secundário e superior francês [1]. Ao publicar sua biblioteca científica, Bouasse contribuiu mais do que qualquer outro na abertura de faculdades de ensino de ciências teóricas e das ciências aplicadas. Também fez duras críticas ao papel da matemática na educação científica. Críticas estas que irão se refletir no discurso e nas atitudes de Pierre como veremos adiante.

\footnotetext{
${ }^{1}$ Discípulo do historiador da ciência Pierre Duhem, é conhecido por escrever a biblioteca científica do engenheiro e do físico, um verdadeiro tratado sobre a física, organizado em 45 volumes.
} 


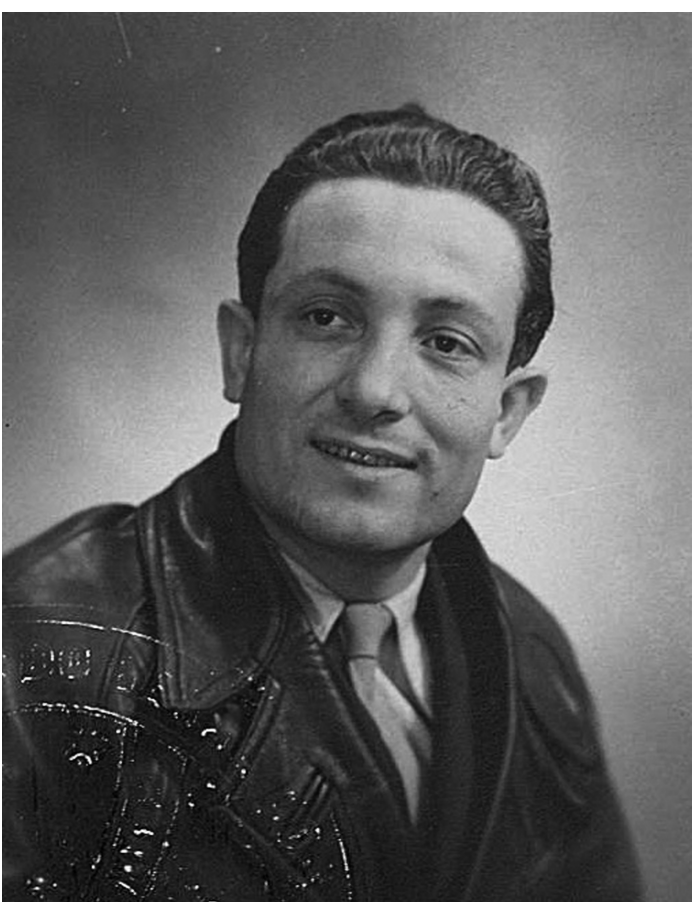

Figura 1: Pierre Henri Lucie. Fonte: Cartões de Imigração do Arquivo Nacional.

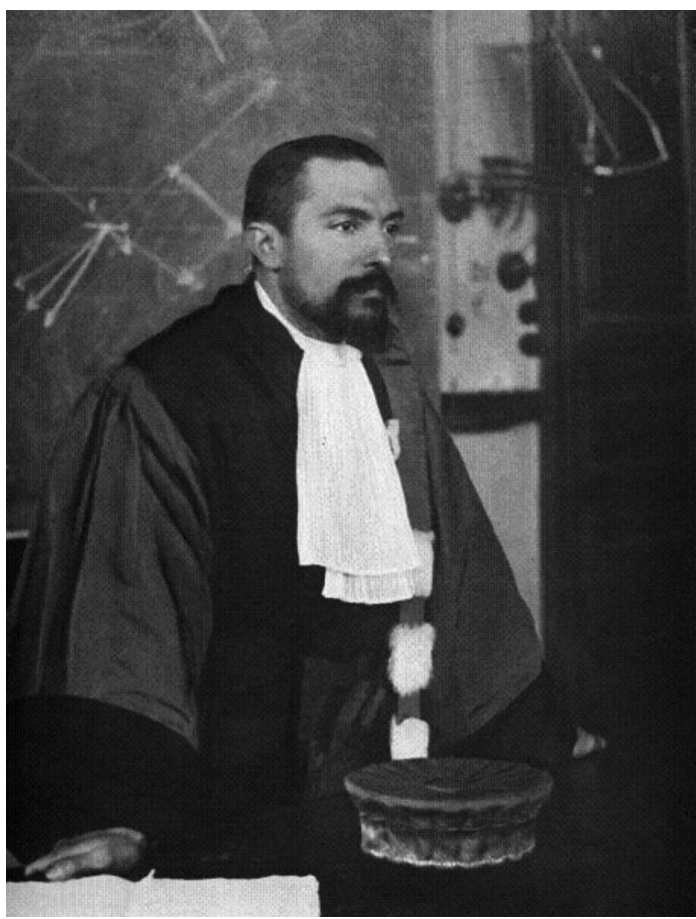

Figura 2: Henri Pierre Maxime Bouasse. Fonte: BibNum Education

Aos 20 anos de idade Pierre conclui seus estudos recebendo o título de bacharel em filosofia e em matemática. Enquanto se preparava para os estudos avançados foi convocado para servir nas forças armadas. O nacionalismo estava em alta na Europa de 1937 quando Pierre foi admitido na École Spéciale Militaire de Saint-Cyף2 situada na região da Bretanha. Após dois anos de estudos na academia foi destacado para atuar na Batalha da França contra a Blitzkrieg alemã. Sua unidade foi derrotada e obrigada a ficar confinado em Arnswalde (OFLAG II-B), um campo de prisioneiros de guerra para oficiais na Polônia (figura 3). A situação não era fácil, e o abatimento envolvia gradualmente os prisioneiros.

Ao perceber esse perigoso efeito da prisão, Pierre reuniu seus companheiros e disse-lhes que os nazistas podiam tirar muitas coisas importantes como a liberdade, a alimentação, o convívio familiar, contudo eles não tinham poder para roubar seu conhecimento nem sua paixão pela natureza. Ele então convida os presos a participarem de um curso acessível de astronomia, ministrado por ele com auxílio de pedaços de carvão para riscar as paredes e tábuas.

O resultado desse gesto altruísta marcou profundamente seus companheiros de infortúnio, mudando sua forma de enfrentar a situação.

Sobreviventes disseram que os momentos maravilhosos de enlevo que o Dr. Pierre Lucie levou aos seus semelhantes humilhados e a si mesmo restituíram à maior parte o ânimo de enfrentar suas vicissitudes. Lucie inspirava muito os prisioneiros porque transmitia-lhes - mais para além da beleza dos conhecimentos cósmicos - o ter encontrado um sentido, no momento mais dramático do sem-sentido do campo nazista. Logo, os prisioneiros disputavam espaço para ficarem mais próximos do grande professor, conscientemente para ouvi-lo melhor e melhor enxergar seus desenhos a carvão, mas inconscientemente para recolherem em suas almas desesperadas um pouco da luz e do calor do cientista $[2]$.

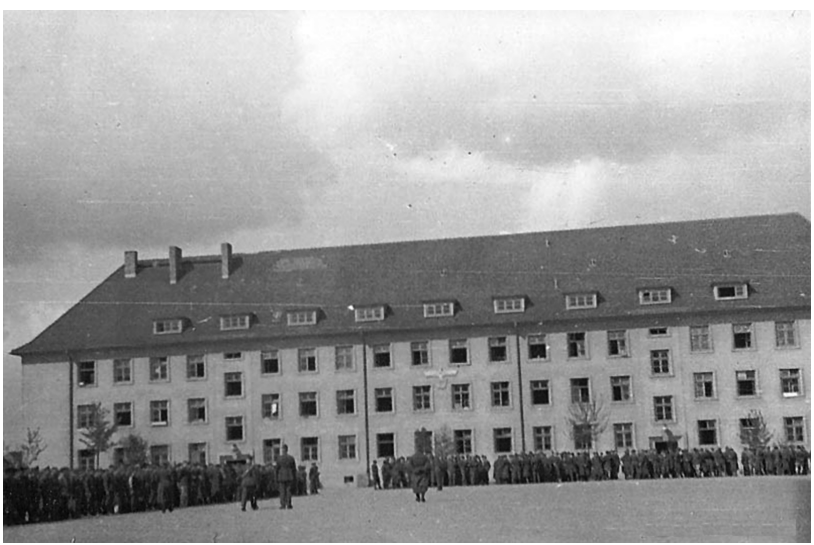

Figura 3: Campo de prisioneiros de Arnswalde. Fonte: Amicale des OFLAGS.

${ }^{2}$ É a principal academia militar francesa, responsável pela formação dos oficiais do exército de terra e da Gendarmerie nacional, uma força policial. 
Devido essa iniciativa de Pierre, de 1940 até o fim da Segunda Guerra Mundial em 1945, os presos organizaram uma espécie de universidade dentro do campo de concentração (figura 4). Pierre participou de cursos de mecânica analítica, óptica, análise matemática, geometria diferencial e até mesmo aulas de mecânica quântica. Essas aulas foram ministradas por outros prisioneiros que conheciam esses conteúdos. Posteriormente esses professores, a exemplo de Pierre, tornaram-se autores de livros didáticos na França como Henri Pailloux, René Gouyon, etc.

Acerca desses cursos de física, Pierre nos disse certa vez que eles:

Eram reconhecidos pela Universidade de Paris, a qual devia outorgar aos aprovados nas provas realizadas nos campos o diplome d'etudes supérieures. A minha vinda para o Brasil no inicio de 1946 me impediu de levar a efeito os trâmites burocráticos referentes a este assunto [3].

Em 1945 com o fim da guerra, Pierre foi libertado em péssimas condições de saúde, "Pierre era pouco mais do que pele e osso" 4]. Por seu serviço a nação francesa, Pierre recebeu das mãos do general Charles de Gaull ${ }^{3}$ a condecoração da Légion d'Honneur ${ }^{4}$ da qual muito se orgulhava.

Contudo após seu retorno para casa, Pierre não estava satisfeito com o clima de debates do pós-guerra, o fato de ter de se posicionar entre um ou outro partido o incomodava. Resolveu então acompanhar um amigo de

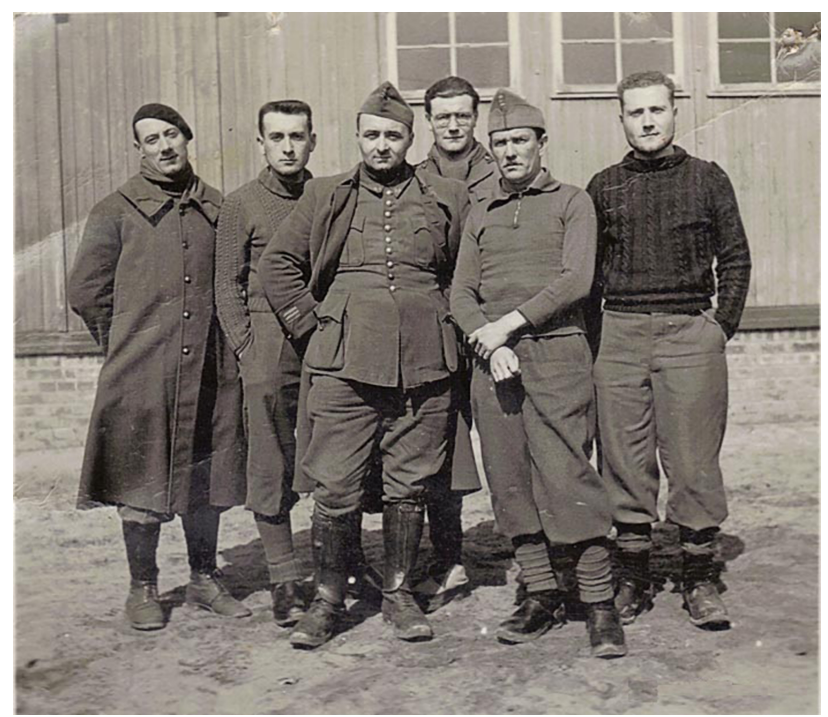

Figura 4: Grupo de prisioneiros de Arnswalde. Fonte: Amicale des OFLAGS.

\footnotetext{
${ }^{3}$ Militar, político e estadista francês que liderou as Forças Francesas Livres durante Guerra.

${ }^{4} \mathrm{~A}$ mais alta condecoração francesa, estabelecida em 1802 por Napoleão Bonaparte. Ele recompensa militares ou civis por excepcionais serviços prestados à França.
}

Toulouse, René Aubrun, que fora nomeado para o posto de diplomata no Brasil. Os dois viajaram a bordo do navio Vapor Groix (figura 5), desembarcando no porto do Rio de Janeiro no dia 31 de maio de 1946.

Inicialmente Pierre consegue trabalho como motorista de caminhão, transportando açúcar da cidade de Campos dos Goytacazes para o Rio de Janeiro. Nos momentos livres consertava e montava rádios para os amigos.

Em pouco mais de dois meses de sua imigração ele se casa com a senhorita Solange Martinelli Diniz, filha de um famoso dançarino carioca, Duque. Deste casamento Pierre também se torna cunhado do pintor Cândido Portinari. Não demorou muito Pierre acaba recebendo de outros compatriotas, um convite para lecionar física no colégio Santo Inácio e posteriormente em cursos preparatórios de vestibular, como o Lutécia.

Renasceu então o professor Pierre Lucie, cujo estilo iria marcar a vida de muitas pessoas, inclusive determinando várias vocações para a área científica. Ele tinha uma habilidade de lecionar que encantava a todos, com muito entusiasmo e força em suas palavras, interagia com seus alunos por meio de arguições, incentivando a investigação e não a memorização. Um de seus clichês era: "não perguntem a mim, perguntem ao sistema, perguntem à natureza!" [3]. Outro aspecto importante de seu método pedagógico estava baseado em experimentos laboratoriais simples, muitos deles desenvolvidos na época do cárcere alemão, utilizando sucata como matéria prima.

Pierre era um homem com forte personalidade, e imitá-lo seria missão impossível. Não obstante, o que ele nos legou foi uma certeza de que é possível associar paixão e razão no magistério das ciências. Seu didatismo era inato, parecendo incorporar em seu intelecto e alma as principais orientações das teorias cognitivistas e de aprendizagem moderna. Sua obsessão pela aprendizagem por meio da interação, observação e experimentação cuidadosa com os objetos físicos

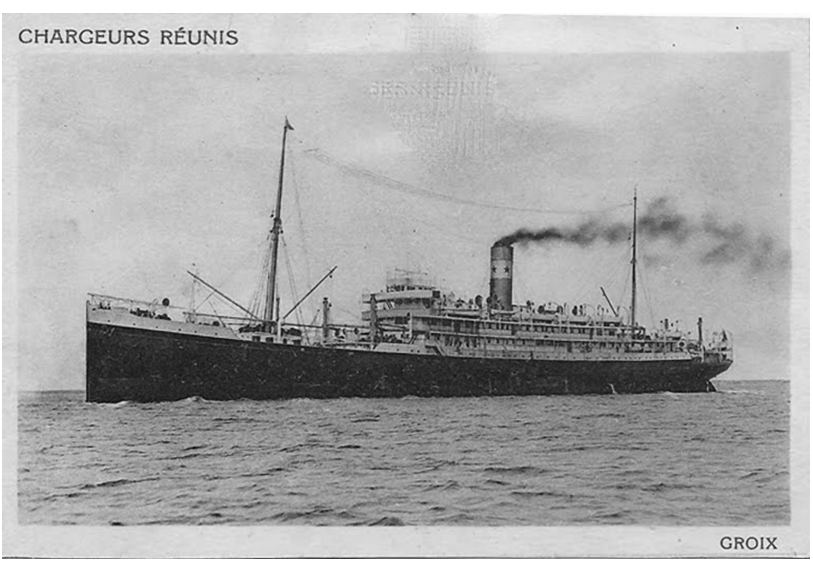

Figura 5: Vapor Groix. Fonte: MyHeritage. 
poderia cunhar-lhe o rótulo de "piagetiano". Mas ele poderia também ser rotulado de "ausubeliano", porque as ideias de aprendizagem significativa, hoje muito em voga entre os educadores no Brasil, eram-lhe intuitivas, e porque ele sempre "ensinou" para que a fundamentação, tanto fenomenológica e analítica quanto sistêmica, fosse estabelecida no apren$\operatorname{diz}[4]$.

Quando lecionava no colégio Santo Inácio, conheceu o Pe. Francisco Xavier Rösel 5 Essa amizade lhe rendeu outro convite, em 1959, para participar da criação do Instituto de Física da PUC-Rio.

Na universidade Pierre foi um dos idealizadores do ciclo básico no ensino de ciências da instituição, experiência que o levou a participar, em 1963, como membro do programa de reformulação do ensino de física americano conhecido como Physical Sciences Study Committee (PSSC) $)^{6}$ Pierre Lucie foi o único latino-americano a participar do PSSC [5]. Esse modelo foi traduzido e implementado na PUC-Rio e em outras universidades brasileiras em 1965.

Seus trabalhos na área de formação de professores fizeram dele um membro da Comissão de Especialistas em Ensino de Ciências no antigo departamento de assuntos universitários do MEC, com a responsabilidade de organizar um currículo universitário básico para todo o país.

\section{O Projeto Física com Martins e Eu}

Durante os anos finais da década de 60 e início dos anos 70, Pierre produziu uma extensa e importante obra de caráter didático voltada para o ensino universitário e médio, o gibi Física com Martins e Eu. Foi escrito em parceria com o cartunista Henrique de Souza Filho (figura 6), conhecido pelo anagrama Henfil 7 . Na história da História em Quadrinhos do Brasil, Henfil renovou o desenho humorístico com seus personagens: os Fradinhos, Capitão Zeferino, Graúna, Bode Orelana, entre outros.

$\mathrm{Na}$ apostila sobre Mecânica o personagem Martins foi inspirado no Fradim Baixim 8 um aluno curioso e contestador que duelava com maestria com seu professor, situação muito similar ao que costumeiramente acontecia nas aulas do professor Lucie. O gibi transformou-se em livro animado de física para o segundo grau em 1969

\footnotetext{
${ }^{5}$ Natural de Linz (Áustria), Pe. Röser era doutor em física pela Universidade de Viena. Um discípulo e colaborador de Victor Hess, prêmio Nobel de física de 1936.

${ }^{6}$ Projeto que foi desenvolvido na década de 1950 pelo Instituto de Tecnologia de Massachusetts (MIT) e traduzido para o português por uma equipe do IBECC, entre os anos de 1961/64.

${ }^{7}$ Também conhecido por sua atuação marcante nos movimentos políticos e sociais do país nos anos 80, lutando contra a ditadura, pela democratização do país, pela anistia aos presos políticos e pelas Diretas Já.

${ }^{8}$ Personagem dos Fradins. Um frade dominicano baixinho, gordinho e muito sacana, que vivia aprontando com outros fiéis.
}

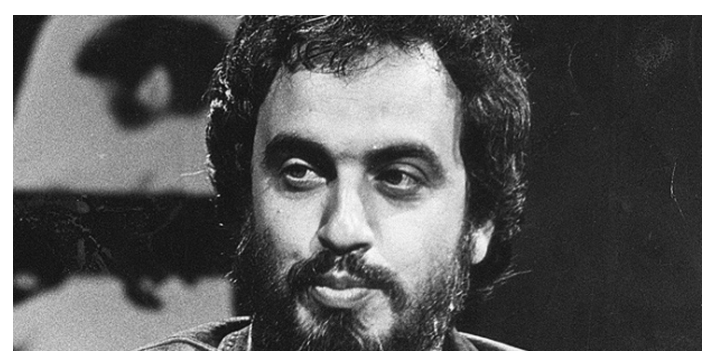

Figura 6: Henfil. Fonte: O Globo.

(figura 7), ocasião em que Pierre foi trabalhar com exclusividade para o Curso Vetor.

No prefácio da edição preliminar podemos ter uma noção das convicções acerca do ensino de física que o autor defendia. Em relação à matematização da natureza, lemos:

Eu tomo posição quanto à maneira de expor. Fujo tanto quanto possível, do formalismo matemático. Ah! Quantas querelas amigáveis tive sobre o assunto! Continuo firme. Cada dia mais. Não por teimosia idiota. Por convicção. Esclareço: não sou contra a matemática na física. Seria tão imbecil, e inócuo, como ser contra o tear mecânico na tecelagem. Conheço bastante a física para saber que o formalismo matemático é uma linguagem, uma ferramenta indispensável. Mas cujo domínio deve suceder, e não anteceder, a percepção 6.

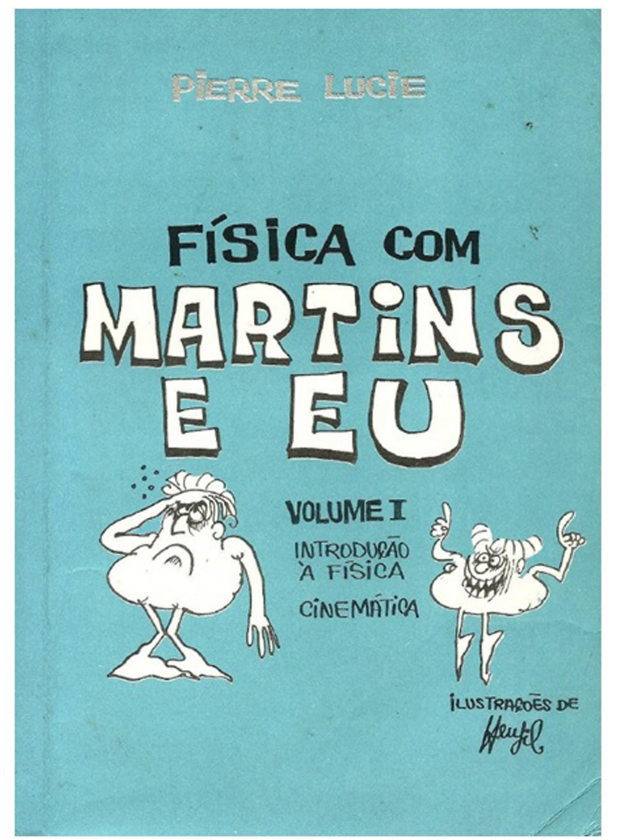

Figura 7: Capa do Livro ilustrada por Henfil. Fonte: Física com Martins e Eu. 
Pierre acreditava que os adolescentes daquela geração eram também cientistas natos. Contudo percebeu tempos depois que essa capacidade estava fortemente ligada ao contexto social em que viviam. Com respeito ao papel de professor e educador de cientistas, um compatriota seu, Maurice Bazin ${ }^{9}$ em certa ocasião afirmou:

O papel de Pierre na educação científica brasileira foi um papel social. A sua atuação pedagógica dinamizadora fazia parte de uma visão do mundo construída pouco a pouco. Por experiência própria sabia que a história não se conta de maneira internalista e que a maneira de ensinar e de aprender se confundem com a maneira de encarar o mundo [3].

Sobre a parceria autor e cartunista do livro, a repercussão alcançada e a importância do seu resgate para o atual cenário educacional lemos:

Trata-se de um livro em que o humor de um e a mordacidade didática do outro se complementam para criar um texto raro para o ensino das "coisas chatas" do programa de física do ensino médio: cinemática e dinâmica. Temos certeza de que Pierre, vivo fosse, criaria hoje um texto mais flexível e menos analítico, adequado aos dias atuais. Não temos dados atuais de pesquisa (e provavelmente nunca teremos!) para saber como foi a interação desse livro com os alunos e se, de fato, por meio da veia crítica do processo de comunicação professor-aluno, conseguiu que os alunos se "ligassem" nos conceitos básicos da física. Mas, por certo, é uma obra que deveria ser resgatada pela comunidade de físicos brasileiros, não só em tributo a Henfil e a Pierre, mas também para que as novas gerações de jovens estudantes brasileiros também possam aproveitar esse formidável acervo didático que, mesmo depois de quarenta anos, ainda não ficou obsoleto 4 .

Em 1975, cerca de trinta anos depois de seu primeiro curso de astronomia em Arnswalde, ele propõe ministrar mais uma vez seu curso, só que desta vez no planetário da Gávea, próximo à PUC.

Foi um enorme sucesso. Segundo os jornais da época, mais de 700 estudantes participaram do curso onde Pierre ensinava a mecânica newtoniana por meio da observação dos fenômenos astronômicos.

Logo em seguida (1978) ele publica um livro baseado nesse curso, A Gênese do Método Científico, onde ele aborda a história e a filosofia da ciência desde a cosmologia grega até as contribuições de Galileu.

Desta época também (1976), com apoio da fundação Cesgranrio, ele inicia a publicação do Boletim Informativo

${ }^{9}$ Maurice Jacques Bazim (1934-2009) foi um grande amigo e colaborador de Pierre Lucie nos tempos da PUC-Rio.
- Contacto Ciências, uma revista mensal voltada aos professores do ensino médio.

No ano de 1982, Pierre foi chamado pelo diretor da Coordenação de Aperfeiçoamento de Pessoal de Nível Superior (CAPES) para coordenar o projeto de melhoria do ensino de ciências e matemática com financiamento do Programa de Apoio ao Desenvolvimento Científico e Tecnológico (PADCT). Com o entusiasmo de sempre, saiu pelo país em busca de projetos e iniciativas de sucesso no ensino. Colecionando várias experiências e conhecendo as desigualdades da educação de nossa nação. Ao retornar de sua empreitada lutou por uma melhor distribuição dos recursos e pela participação dos professores da educação básica nas decisões de aprovação de projetos.

Em 1984 retornou ao Rio de Janeiro para estar mais perto da família e continuar sua pesquisa. Passou seus últimos meses de vida estudando e escrevendo programas de computador para demonstração gráfica de experimentos do laboratório de ensino. No dia 12 de setembro de 1985, com 68 anos, Pierre Lucie deixou esta vida, após sofrer um infarto agudo do miocárdio, deixando a ex-mulher, Dona Solange, seu único filho, Pierre Henri Antoine Diniz Lucie e netos.

Entre as várias homenagens póstumas a ele destaco as sessões solenes de 1985 do instituto de física da PUCRio, com o depoimento dos professores Luciano Videira e Sérgio Costa Ribeiro e a Sessão em homenagem a Pierre Lucie no VI Simpósio Nacional de Ensino de Física (SNEF) de 1995 ocorrido na Universidade Federal Fluminense (UFF), em Niterói.

Nas comemorações dos 25 anos do projeto Fundã ${ }^{10}$ da Universidade Federal do Rio de Janeiro (UFRJ), em 2008, houve uma sessão em homenagem ao professor Lucie. Na ocasião foi instituído o prêmio Pierre Lucie, com o objetivo de valorizar e destacar o trabalho acadêmico de docentes que atuam na melhoria das disciplinas de graduação.

\section{Análise do Livro}

Esta análise faz parte de um trabalho de pesquisa concluído recentemente [7, onde foi proposta a avaliação do livro Física com Martins e Eu, com base nos critérios da ficha de avaliação pedagógica presentes no guia dos livros didáticos do certame de 2015 .

As primeiras palavras do autor no prefácio do livro são os dois objetivos que ele tinha em mente ao escrevê-lo. Primeiramente uma tentativa de desmitificar a disciplina, que para muitos é destinada a pessoas superdotadas intelectualmente, sendo necessário enorme talento para entendê-la. Em relação a isso Pierre explica que:

O Físico no seu laboratório tem a mesma vontade de viver sua vida, as mesmas preocupações fundamentais, as mesmas alegrias,

\footnotetext{
${ }^{10}$ Grupo de pesquisa para a melhoria do ensino das ciências e da matemática, buscando a valorização do professor.
} 
mas também as mesmas angústias que o pintor, o músico, o homem do teatro, o romancista. Desde que se é um bom profissional, as regras do jogo são praticamente as mesmas 6].

O segundo objetivo era mostrar que o estudo da natureza e suas leis são agradáveis, a tal ponto que podemos nos seduzir. O segredo para isto está na tentativa constante de falar da física como ela realmente é, sem pompa, ou formalismos matemáticos extremos. Deve-se ensinar física de forma lúdica, mostrando o fenômeno, ilustrando tanto quanto possível.

O livro foi escrito e produzido para os alunos do ensino médio, com uma preocupação que ele possa contribuir para a formação do cidadão. Ele vai ao longo do texto tentar desenvolver o bom senso, a intuição dirigida, a observação e a criticidade.

Em vista disso o autor escolhe certos temas em detrimento de outros não propícios à formação, usando linguagem acessível, evitando o formalismo matemático que tende a substituir a compreensão pelo mecanismo.

A utilização dos diálogos entre as personagens ao longo do texto contribuiu para garantir que os objetivos do autor pudessem ser atingidos. O Professor é a primeira personagem e representa o próprio Pierre Lucie, já Martins é seu aluno irritante, que constantemente está questionando as falas do professor (figura 8). Algumas vezes, o professor admite que errou; outras vezes, ele consegue convencer o aluno. Os dois conversam, discutem, chegam a perder a paciência e a brigar, mas há respeito e vontade em se chegar a uma conclusão satisfatória, nessas discussões.

"A Física com Martins e Eu", que é um primor de livro, em que ele se coloca, está lá a caricatura do Pierre, ele se coloca várias vezes embaraçado por um aluno que faz perguntas e faz perguntas de forma irreverente e às vezes de forma impertinente, mas ele cultivava muito isso, esse espírito crítico nos seus alunos e era uma coisa que ele sempre cultivava e pretendia que nós tivéssemos. Então Martins é um pouco desse aluno símbolo que ele pretendia que nós fôssemos, aluno que não larga o professor, que sempre tem uma dúvida para deixar o professor encurralado 8].

Foram produzidos dois volumes da obra Física com Martins e Eu em 1969 e 1970, o material abrange apenas os conteúdos da mecânica, introdução a física e cinemática no volume I e dinâmica da partícula, com dois fascículos, no volume II.

O texto segue intercalado com diálogos em quase todas as páginas. Também existem figuras, desenhos ou mesmo fotografias de experimentos. Ao final de cada capítulo existe uma lista de problemas propostos, alguns deles devem ser discutidos com o professor em sala de aula.

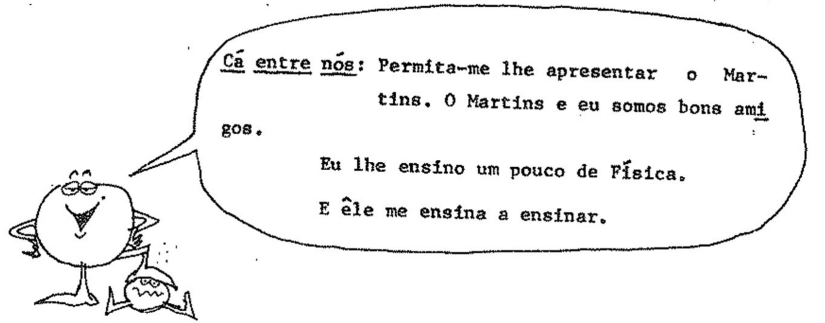

Figura 8: Apresentação das Personagens. Fonte: Física com Martins e Eu.

No final do volume encontramos uma lista exaustiva de exercícios de revisão no formato de perguntas de múltipla escolha.

O livro foi escrito de maneira a conversar com o leitor, com vários questionamentos que induzem a reflexão. A linguagem utilizada está alinhada com o vocabulário jovial da época, tornando a leitura muito prazerosa. A presença de ilustrações dá um toque de irreverência e humor. O conjunto de todas essas estratégias de escrita leva esse livro a ter uma condição única dentro do contexto editorial de livros didáticos.

Em uma resenha do Prof. Roberto de Andrade Martins 11 ele oferece algumas informações pessoais que pode nos dar uma pista sobre uma das personagens do livro.

Em 1965, quando estava cursando o primeiro ano do ensino médio, comecei a ter grande interesse por física. Os padres jesuítas do colégio me estimularam a entrar em contato com o padre Francisco Xavier Roser (1904-1967), fundador do Instituto de Física da PUC-Rio, para possivelmente fazer a graduação em Física naquela universidade. Visitei a PUC em 1966, e nessa ocasião o padre Roser me apresentou ao prof. Pierre Henri Lucie, que estava trabalhando na tradução e adaptação para o Brasil do livro didático de física do projeto norte-americano PSSC (Physical Sciences Study Committee). Pierre me estimulou a estudar o PSSC por conta própria, mandando cartas para ele sobre seus estudos. Estudei efetivamente todos os volumes do PSSC, e fui enviando meus comentários e dúvidas para o professor Lucie. Posteriormente, no entanto, optei por fazer minha graduação em Física na USP e não na PUC-Rio e perdi contato com o professor Pierre Lucie. No entanto, parece que ele se divertiu bastante com minhas dúvidas e questionamentos, e isso parece tê-lo motivado a utilizar meu sobrenome para o seu personagem Martins. Ia me esquecendo de dizer: desde criança,

\footnotetext{
${ }^{11} \bar{E}$ um físico, filósofo, historiador da ciência e escritor muito prestigiado na comunidade acadêmica brasileira.
} 
no colégio, eu era conhecido pelo meu sobrenome 9 .

Hipóteses à parte, iremos agora analisar a coleção, usando como parâmetro os critérios da ficha de avaliação pedagógica do PNLD [10]. Estes são divididos em cinco blocos, organizados a partir das exigências do edital de convocação do PNLD 2015.

\subsection{Legislação e Cidadania}

O primeiro Bloco, intitulado Legislação e cidadania, o PNLD se preocupa em avaliar as obras didáticas observando o

Respeito à legislação, às diretrizes e às normas oficiais, relativas ao ensino médio (Constituição Brasileira; ECA; LDB 1996; DCNEM; Resoluções e Pareceres do CNE), assim como observância de princípios éticos e democráticos necessários à construção da cidadania e ao convívio social [10].

Para tanto são elencados 13 indicadores que precisam constar de maneira expressa e/ou implícita no texto do livro didático.

Como o livro foi escrito em uma época anterior a muito desses documentos ${ }^{12}$ seria muito injusto tentar avaliar esse quesito. Contudo mesmo assim é possível encontrar no livro de Pierre exemplos de respeito a essa legislação futura. Quando o autor escreve que:

A partir do fenômeno e de sua representação gráfica, tentemos desenvolver aquelas qualidades tão importantes para quem passa da infância para a maturidade: o bom senso, a intuição dirigida, a observação, o senso crítico; em resumo: a arte de raciocinar bem. Perdoem-me por grifar esse "bem". É que tanta gente raciocina mal a partir de premissas falsas que o verbo já perdeu muito de sua força de expressão. Mas voltando àquelas qualidades que enumerei acima, vejam: são no fundo as qualidades que nós todos gostaríamos de reconhecer em qualquer cidadão bem formado. E por acaso não é exatamente a formação do adolescente, do futuro cidadão, que deveria ser a tônica do ensino médio? De modo que fui naturalmente levado a definir o possível público deste livro: eu quis que ele pudesse contribuir à formação do cidadão 6 .

Percebe-se o reconhecimento do ensino médio como etapa final da Educação Básica, e da criança e do adolescente como cidadãos, que são dois dos indicadores desse bloco. Com relação ao décimo primeiro indicador

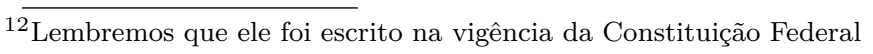
de 1967. referente a reconhecimento da ciência como conjunto de conhecimentos sistematizados ao longo da história o autor prossegue:

Você deve ter a consciência, naturalmente, que o barco em que embarcou está no meio da viagem. Não começou a andar com você, nem terminará. Os primeiros passos (e perdoe-me de dar pernas a um barco), foram dados há alguns milênios, por gregos ou chineses, ou egípcios, quem sabe? A bem da verdade, devemos reconhecer que o primeiro ser humano que olhou para sua imagem na água de uma fonte e deslumbrou-se com o que via, e procurou uma explicação ao fenômeno, tinha as qualidades fundamentais de um cientista 6 .

Boa parte do texto do livro busca favorecer a autonomia intelectual e o pensamento crítico, quase sempre após a explicação de um conceito chave ou o surgimento de uma informação nova, ilustrações do Henfil são colocadas justamente para problematizar o conteúdo abordado pelo texto.

Entretanto alguns indicadores desse bloco não foram respeitados, em especial a presença de armas de fogo, tacapes, chicotes, bombas e uso da violência, mesmo que de forma cômica, ferindo os valores éticos e sociais da pessoa e da família como definidos no quinto indicador.

O sexto indicador sobre a presença de mensagens que veiculam publicidade é violado no segundo volume da obra quando da descrição do padrão de medição de forças o autor escreve: "ah! Já sei. Fixo as pontas, com um pouco de cola Polar, sobre dois quadradinhos de cartolina..." 11.

Com relação à integração de conhecimentos gerais na perspectiva da interdisciplinaridade e da contextualização muito pouco foi encontrado. Também questões socioambientais e de sustentabilidade não foram contempladas. Como exposto anteriormente, na época não se tinha essa preocupação em interligar as disciplinas ou oferecer contextos mais amplos no ensino. É por isso que não encontramos essas temáticas no texto do livro.

\subsection{Abordagem Teórico-Metodológica e Proposta Didático-Pedagógica}

O segundo bloco do PNLD possui 14 indicadores que verificam a:

Adequação e coerência da abordagem teóricometodológica assumida pela coleção com a proposta didático-pedagógica desenvolvida e com os objetivos visados. A coleção deve: escolher uma abordagem metodológica capaz de contribuir para a consecução dos objetivos educacionais em jogo; ser coerente com a abordagem assumida, do ponto de vista dos conteúdos de ensino apresentados, bem como 
dos recursos propostos; respeitar a perspectiva interdisciplinar na apresentação e abordagem dos conteúdos 10 .

Como ocorreu no primeiro bloco, também foi possível encontrar a presença deles no livro. Por exemplo, o primeiro indicador avalia a coerência entre a fundamentação teórico-metodológica e o conjunto de textos, atividades e exercícios da obra. Na introdução o autor expõe algumas orientações didático-pedagógicas quando diz:

Eu gostaria que você iniciasse a sua incursão pela Física com o estado de espírito conveniente. E, se possível, esqueça que haverá provas e exames para testar seu grau de aprendizagem. Não estude Física para "fazer problemas". Resolver problemas, é claro, será necessário para verificar se você realmente entendeu o que está estudando, mas nunca deve constituir-se em objetivo final. Você vai estudar Física para entender melhor o mundo em que vivemos. Os problemas reais são problemas oferecidos pela Natureza, são os desafios que o esperam a cada passo, a cada instante, se você sabe "ver" o que está a seu redor 6].

O conjunto de textos foi escrito visando à compreensão dos fenômenos naturais ligados a Física, ele o faz exaustivamente dialogando com leitor para que essa compreensão seja alcançada. Alguns dos exercícios propostos do volume $]^{13}$ buscam retomar os diálogos do texto para um aprofundamento do tema.

Em relação à organização percebe-se uma progressão dos conceitos mais simples para os mais complexos, existe também uma seleção de conteúdos por parte do autor para favorecer a formação.

Eu trato em termos elementares a Teoria Cinética dos Gases, porque há um modelo simples que permite entender o que é a pressão em um gás, e temperatura. Mas não falo de Hidrostática porque não existe nesse nível nenhum modelo que permita entender o mecanismo da pressão em um líquido. Eu demoro no estudo dos pulsos e de ondas que se propagam em meios elásticos, porque assim fazendo eu construo uma base sólida para o estudo dos fenômenos de difração e de interferência em Ótica. E o estudo desses fenômenos é formativo porque eles conduzem a uma compreensão melhor da Física do átomo. Mas eu não daria nenhum passo a mais no sentido da formação, ao enumerar as leis das cordas ou dos tubos sonoros. Eis porque não há Acústica neste livro 6].

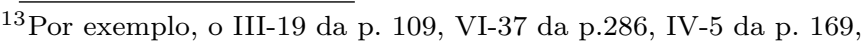
VIII-20 da p. 411, etc.
}

Os demais indicadores desse bloco também estão contemplados, exceto os seguintes: o oitavo que verifica a utilização de contextualização e interdisciplinaridade na organização didático-pedagógica dos conteúdos, o nono relacionado à articulação transdisciplinar, o décimo que exige a presença da história da ciência dialogando com o assunto desenvolvido e o décimo primeiro indicador que propõem as discussões das relações CTSA ${ }^{14}$ como suporte para a criticidade. Em relação à história da ciência até que aparece alguma coisa. Contudo é muito empobrecida, se reduz a biografias em formato de apêndice, no final dos capítulos ${ }^{15}$ e descobertas isoladas, que não condizem com o contexto do desenvolvimento científico.

\subsection{Conceitos, Linguagens e Procedimentos}

O bloco de número três vai observar aspectos ligados a correção e atualização de conceitos, informações e procedimentos presentes no livro didático.

Respeitando tanto as conquistas científicas das áreas de conhecimento representadas nos componentes curriculares, quanto os princípios de uma adequada transposição didática, foram excluídas as obras que: apresentaram de modo incorreto, descontextualizado ou desatualizado conceitos, informações e procedimentos; utilizaram de modo incorreto, descontextualizado ou desatualizado esses mesmos conceitos e informações, em exercícios, atividades, ilustrações ou imagens [10].

Esse bloco apresenta dezesseis indicadores de avaliação. Durante a análise dos livros não foi encontrado nenhuma situação de erro na descrição e utilização dos conceitos físicos nem a presença de conteúdos desatualizados. Como se trata de uma obra do inicio dos anos 70, muita coisa já mudou, no entanto essas mudanças estão mais ligadas à física de partículas do que propriamente na mecânica clássica.

O sexto indicador, por exemplo, verifica se o livro evita somente a utilização de situações idealizadas ou impossíveis, e quando usa se expõe ao leitor que tal situação se trata de uma abstração. Podemos observar isso no exemplo a seguir:

O que realmente importa no movimento da partícula é a sua aceleração. Porque a velocidade, no fundo, pode ter, um determinado instante, o valor que quisermos. Basta escolher convenientemente o referencial em que estudamos o movimento... quando eu digo "valor que quisermos", não é bem isso. Não adiantaria querermos uma velocidade superior (ou mesmo igual...) à velocidade da luz

\footnotetext{
${ }^{14}$ Iniciais para Ciência, Tecnologia, Sociedade e Ambiente, um dos enfoques metodológicos para o ensino de ciências.

${ }^{15}$ Por exemplo, no volume II, capítulo X, p. 184, encontramos uma pequena biografia de Galileu e Newton.
} 
no vácuo... Mas a aceleração é a mesma em qualquer referencial... 11]

O sétimo indicador sugere a inclusão de problemas apresentando enunciados contextualizados da situaçãoproblema, capazes de permitir debates acerca do conteúdo apresentado. Fazendo uma busca na coleção foi possível encontrar alguns exemplos de respeito a esse critério.

No problema proposto X-11, do capítulo X volume II sobre a primeira lei de Newton, o autor utiliza um trecho do romance de Julio Verne, Da Terra à Lua, contextualizando uma situação aberta o suficiente para estimular estimativas e considerações por parte do professor e do aluno (figura 9)

Em 1865, Jules Verne escreveu um de seus famosos romances de antecipação intitulado: "Da Terra à Lua". Nesse livro, Verne imagina que um gigantesco canhão de $300 \mathrm{~m}$ de comprimento atira um obus cuja velocidade, na saída da boca, é $11 \mathrm{~km} / \mathrm{s}$. A nave verniana dirige-se para a Lua. À medida que ela se afasta da Terra, a aceleração gravitacional da Lua (dirigida para o centro da Lua) vai aumentando. Enquanto a aceleração devido à Terra supera em módulo a aceleração devido à Lua, Verne representa os viajantes em pé sobre a extremidade da nave mais próxima da Terra, mantidos pela atração Terrestre. Na região em que as duas acelerações são diretamente opostas, tendo portanto uma soma nula, Verne representa os tripulantes flutuando na nave. $\mathrm{Na}$ vizinhança da Lua, onde a aceleração devida à Lua supera em módulo a aceleração devido a Terra, Verne representa os tripulantes em pé sobre a extremidade mais próxima da Lua, mantidos pela atração do nosso satélite natural. No início da viajem, um dos cachorros levados pela expedição, morre. A tripulação dispõe do corpo do animal passando-o para fora da nave através de uma abertura adequada. No entanto, os passageiros observam que o corpo do cachorro acompanha a nave até a Lua. Discuta criticamente as soluções de Jules Verne, desde o lançamento do obus 11].

O décimo indicador que versa sobre a presença de conteúdos ligados a Física Moderna e Contemporânea não foi localizado, já em relação a expressões matemáticas e fórmulas, todas estão acompanhadas de enunciados e expressas de forma adequada inclusive com suas deduções.

A parte experimental do livro é notável, muitos exemplos em todos os capítulos, estimulando a perspectiva investigativa na sua plenitude (teoria, observação, pensamento e linguagem). Esses experimentos são fáceis de ser reproduzidos e não oferece riscos a integridade física dos alunos. Sob a convicção do autor acerca da experimentação em sala de aula lemos:

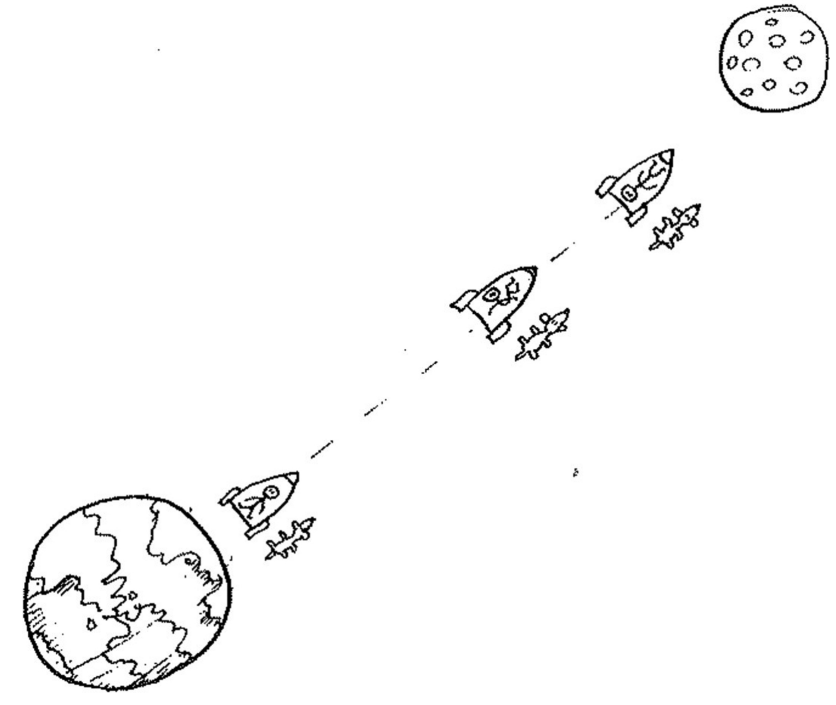

Figura 9: Ilustração do problema X-11. Fonte: Física com Martins e Eu.

Se quisermos interessar os jovens no estudo da Física, falemos de Física. Isto é, em primeiro lugar, do fenômeno. E se possível, mostremos. Já sei! O bendito argumento da falta de laboratórios acessíveis a esse nível. Mas sejamos de boa fé! Com um pouco de imaginação e de boa vontade, muita coisa pode ser feita. Isto é, quando eu falo de pêndulo, eu mostro primeiro o pêndulo. Acontece que eu tenho geralmente nos bolsos pedaços de barbante, elásticos de escritório, e mesmo alguns prendedores de roupa. É incrível o que a gente consegue fazer com sucata caseira 6].

Alguns dos exemplos contidos no livro mostram isso que o autor quis dizer, pois se consegue resultados plausíveis sem muitos riscos. Alguns exemplos estão descritos a seguir:

Faça a experiência seguinte: amarre uma pedra na extremidade de um barbante de mais ou menos um metro de comprimento, e faça oscilar o pêndulo que você fabricou. Meça com um relógio o intervalo de tempo que abrange 10 oscilações completas (ida e volta). Digamos que você achou 20 segundos. O fenômeno que você observou foi a oscilação de um pêndulo. Essa observação traduziu-se até agora por uma medida. Você pode concluir que o período do seu pêndulo é igual a dois segundos. E daí? Uma maquina registradora podia chegar ao mesmo resultado. Mas repita a experiência reduzindo à metade o comprimento do barbante. Você acha agora 17 segundos para dez oscilações. Você conclui então que o período do pêndulo depende do comprimento [6]. 
Em outro trecho do livro tem um interessante experimento onde pedras são amarradas em um barbante e lançadas de certa altura. Se o espaçamento entre elas é uniforme, a queda gera um som acelerado (figura 10). Se as distâncias entre elas seguem a relação dos números ímpares, de baixo para cima, o som resulta de intervalos regulares. Mostrando ser a audição o sentido mais indicado para percebermos o movimento de queda livre.

Da janela do quarto andar de um edifício, um colega seu segura a extremidade de uma corda ao longo da qual você fixou, de metro em metro, um chumbo ou uma pedra pequena. Você está na calçada onde dispõe, debaixo da corda, um pedaço de tábua. O colega larga a corda. Os chumbos caem sucessivamente sobre a tábua. Descreva quantitativamente o que você ouve. Como é que você deveria dispor os chumbos ao longo da corda se você quiser ouvi-los cair sobre a tábua a intervalos de tempos iguais? Você pode e deve procurar realizar essa experiência! [6].

Este terceiro bloco apresentou o melhor resultado do livro, com o cumprimento de 12 dos 16 indicadores. Só não sendo melhor devido novamente a falta de articulação do texto com a dimensão histórica da produção do conhecimento e da dimensão vivencial dos alunos.

\subsection{Manual do Professor}

O quarto bloco da ficha de avaliação pedagógica oferece parâmetros para avaliação do manual do professor, verificando se o mesmo atende as características e finalidades para qual foi escrito.

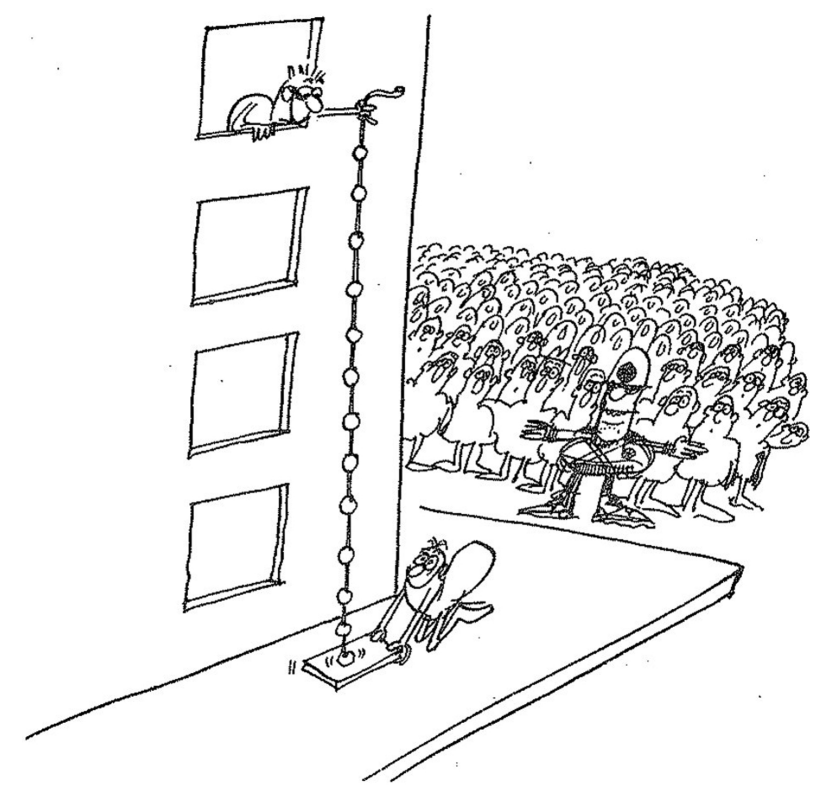

Figura 10: Ilustração do experimento V-23. Fonte: Física com Martins e Eu.
Física com Martins e Eu, não possui um manual do professor como costumamos observar nos livros atuais, porém o prefácio da edição preliminar e seus anexos contêm algumas informações que se encaixam a quatro dos dezenove indicadores desse bloco.

Os indicadores quanto à exposição dos objetivos da proposta didático-pedagógica, a organização geral da obra, sugestões experimentais e respostas para as atividades do livro, estão presentes.

Algo que chama a atenção é a ausência completa de referências bibliográficas no texto dos dois livros. A única indicação de orientação acadêmica está explicita na figura de Henri Bouasse e no projeto PSSC de ensino de Física.

Primeiro ao meu mestre Bouasse. Tudo ou quase tudo que eu disse nêste prefácio, foi dito, repetido, escrito e proclamado por êle... há uns quarenta anos em média. Que os que pretendem "inovar" em 1969 tenham o cuidado de volver às fontes preciosas que constituem os prefácios do seu tratado de Física... em 35 volumes, escalonados entre mais ou menos 1914 e1937. Segundo ao Physical Science Study Committee (PSSC), que realmente imprimiu um rumo novo no ensino da Física de grau médio nos Estados Unidos. Trabalhei durante um ano no Education Development Center, onde foi elaborado, e continua sendo ampliado, o programa do PSSC. Declaro sem rodeios que fiquei profundamente "marcado" por essa experiência extraordinária [6].

\subsection{Projeto Editorial}

O quinto e último bloco vai verificar a adequação da estrutura editorial e do projeto gráfico com os objetivos didático-pedagógicos da coleção. Dos dez indicadores listados, os quatro primeiros são contemplados, pois a coleção é organizada, coerente e funcional, apresenta legibilidade gráfica. O texto principal está em preto e branco com títulos e subtítulos hierarquizados.

A fonte da letra utilizada é o Courier New, os títulos são identificados por algarismos romanos e estão em caixa alta. Os subtítulos são sublinhados no corpo do texto e as letras utilizadas nos diálogos ilustrados são de fôrma.

Existe no inicio de cada volume um índice com a indicação e localização do conteúdo. Em ambos os livros existe um documento intitulado errata, colocado posteriormente a publicação onde são informados os erros da obra e sua respectiva correção. Mas não livra a obra de outros erros já que esta era uma época em que as impressões utilizavam pouco ou quase nada de recursos computacionais.

Um ponto positivo está na colocação exata das ilustrações para dar entendimento ao leitor quanto ao conteúdo abordado. Estas posições foram pensadas e debatidas pelo autor e o desenhista durante a redação do texto pre- 
liminar, e mostra a preocupação do autor em esclarecer o fenômeno sem precisar recorrer à matemática.

A presença de erros de impressão, a ausência de ilustrações retratando a diversidade étnica, social e cultural do país, bem como falta de créditos nas fotos, legendas nas tabelas e outras exigências normativas prejudicaram o livro nessa avaliação.

Existem ainda nos critérios do PNLD os mesmos cinco blocos para avaliação específica dos Objetos Educacionais Digitais (OEDs). Em virtude da inexistência desses ODEs na obra de Pierre, encerra-se aqui as análises do seu livro didático.

\section{Conclusão}

O livro didático Física com Martins e Eu, apresenta uma proposta de ensino de Física capaz de levantar algumas reflexões importantes. Primeiramente destaco a interação do livro com o leitor que muito se assemelha com a interação entre professor e o aluno. A linguagem utilizada e a presença do gênero textual história em quadrinhos foram decisivas para dar as condições necessárias à compreensão do texto.

A linguagem dialógica utilizada teve o cuidado de inserir as expressões e termos científicos da Física de maneira muito natural, pois o contexto dos diálogos ajudou nessa inserção e interpretação. Não há perdas quanto ao conteúdo se comparado com outros livros convencionais.

A dimensão experimental é a tônica do livro, "o que eu quero dizer é o seguinte: entre ensinar brincando e ensinar chateando, eu prefiro ensinar brincando" [6]. Essa sua maneira de apresentar o conteúdo de forma experimental, iniciando pelo fenômeno e buscando respostas na natureza e não na matemática, confere esse lado lúdico ao livro.

Existe algo que as aulas práticas provêem aos alunos que nenhuma outra oportunidade se iguala. $\mathrm{O}$ encontro com o inesperado. O importante de uma aula prática não é o que dá um resultado esperado, mas é quando não dá! É aquele momento em que você precisa pensar para tentar descobrir o que esta acontecendo. Como dito certa ocasião por Pierre:

São os instantes em que aceitamos a discussão, com os nossos discípulos, de problemas não preparados de situações imprevistas; são as ocasiões em que dividimos com eles as incertezas, as perplexidades, as indecisões. Mas são também os instantes em que podemos transmitir diretamente, sem artifícios, o que as crianças e os jovens vêm procurar, talvez inconscientemente, nos bancos de escola: a maneira de crescer intelectualmente, a arte do raciocínio que dissipa magias, um começo de satisfação à ânsia de ser gente [12].
A Física utiliza-se de muitos modelos, que são em geral idealizados. Quando nos propomos a experimentar, entenda-se arriscar, dialogamos com o imprevisto. Muitas das propostas apresentadas em Física com Martins e Eu, criam esse diálogo com o imprevisto, elevando nossa condição de aprendizagem.

Todos esses elementos anteriormente citados estimulam o aluno a interessar-se pela Física, pois a todo instante o livro vem e provoca o leitor com perguntas desconcertantes, cuja resposta não parece ser tão óbvia. Chega até mesmo ao extremo de insistir que o leitor faça uma tarefa antes de prosseguir com sua leitura! Esse é o jeito Pierre Lucie de ensinar divertindo.

O material publicado foi escrito para o ensino médio, podendo também ser utilizado como apoio para a universidade. Alguns trechos do livro, por exemplo, exploram conteúdos de cálculo como o limite e as derivada:16 Para os docentes (atuais ou futuros) a coleção oferece boas sugestões de abordagem aos temas da mecânica e um banco de mais de 500 questões, além dos experimentos.

Após passar pelo crivo do PNLD 2015, existem muitos aspectos que poderiam ser ajustados para dar ao livro melhores condições de participação no certame. Em termos percentuais, os cinco blocos de avaliação pedagógica apresentaram algo em torno $56 \%$ de respeito aos indicadores exigidos. Os blocos mais problemáticos foram o quarto, referente ao manual do professor e o primeiro de legislação e cidadania.

Os blocos mais bem avaliados foram o terceiro, que trata de conceitos, linguagens e procedimentos e o bloco de abordagem teórico-metodológica e proposta didáticopedagógica.

O livro didático para ser aprovado precisa respeitar todos os indicadores e, além disso, precisa contar com os OEDs para ser aceito no rol de obras que serão escolhidas pelas escolas do país. Infelizmente chega-se à conclusão que a coleção Física com Martins e Eu, não seria aprovada por algumas das razões expostas acima, mas também por ela ser uma coleção inacabada! Os volumes produzidos não contemplam todo o conteúdo típico de um curso de Física para o ensino médio, apenas os conteúdos trabalhados no primeiro ano do curso.

Buscar razões para explicar porque Pierre não completou essa coleção, fica difícil de responder. Talvez a grande quantidade de atribuições que tinha, a maioria delas fora da sala de aula, deve ter dificultado a continuação do projeto.

Em contato com o professor Roberto de Andrade Martins que escreveu uma pequena resenha do livro [9], soube que um dos possíveis motivos da não conclusão do projeto foi que, na época, a coleção não alcançou o sucesso esperado. Também fui informado que em junho de 2005 houve uma tentativa para a reedição da obra. Seria feito pela editora Livraria da Física, por iniciativa do professor Martins. Na reunião do representante da editora com os herdeiros legais, os filhos de Pierre e Henfil, infelizmente

\footnotetext{
${ }_{16} \mathrm{Na}$ época esses conteúdos pertenciam ao currículo do ensino médio.
} 
não foi possível chegar a um acordo. O que nos resta são as cópias disponíveis on-lin ${ }^{17}$ ou garimpar edições impressas nos sebos do Rio de Janeiro.

A avaliação proposta pelo PNLD, em tese, busca melhorar os conteúdos do livro didático, usando critérios técnicos que refletem muitas das tendências de pesquisa em ensino de ciências. Dentre tantos critérios, posso destacar os seguintes:

- Integração de conhecimentos gerais na perspectiva da interdisciplinaridade e da contextualização;

- Apresentação da ciência como um conjunto de conhecimentos sistematizados, produzidos socialmente ao longo da história, cuja função visa à compreensão e transformação da natureza e da sociedade;

- Coerência com a abordagem teórico-metodológica e a proposta didático-pedagógica desenvolvida ao longo dos textos e das atividades propostas;

- Combate ao ensino da física de forma compartimentalizada;

- Articulação do conteúdo com a história da ciência;

- Discussões sobre as relações CTSA;

- Estímulo ao posicionamento crítico, bem como o incentivo a leitura de artigos, de textos de divulgação científica, jornais, tabelas e gráficos;

- A atualização dos conteúdos;

- Utilização do laboratório para realização de investigações e experimentos.

Nesse sentido, o advento do PNLD pode ser considerado um grande avanço, contudo como somente as grandes editoras conseguem dar conta dos prazos e das demandas estabelecidas pelos editais, o mercado fica concentrado nas suas mãos. No caso da Física: Saraiva, Moderna, Scipione e Ática foram as únicas editoras a terem livros aceitos em todos os certames do PNLD.

Outro problema que está sendo evidente a cada nova edição é o que chamo de homogeneização. A maioria dos livros aprovados é muito parecida, a menos do projeto gráfico e da estrutura editorial todo o resto é muito análogo. A forma de abordagem, o conteúdo escolhido, os exercícios, não dando espaço para invocações semelhantes à analisada nesse trabalho.

Acredito que o PNLD precisa ser repensado para que possa dar conta dos problemas apontados aqui e de outros que porventura não foram discutidos. Pois não recomendar o uso do livro Física com Martins e Eu acabou se tornando uma grande incoerência.

A obra de Pierre Lucie não é apenas mais um livro de Física, é uma obra que mostra na prática um jeito diferente de compreender a Educação. Um livro de grande valor, por traduzir a personalidade do autor e de refletir de alguma maneira parcelas das personalidades daqueles

\footnotetext{
${ }^{17}$ Hospedado nos servidores da Internet Archive foi possível acessar os dois volumes pelo endereço: https://archive.org/details/Fisica_Com_Martins_E_Eu
}
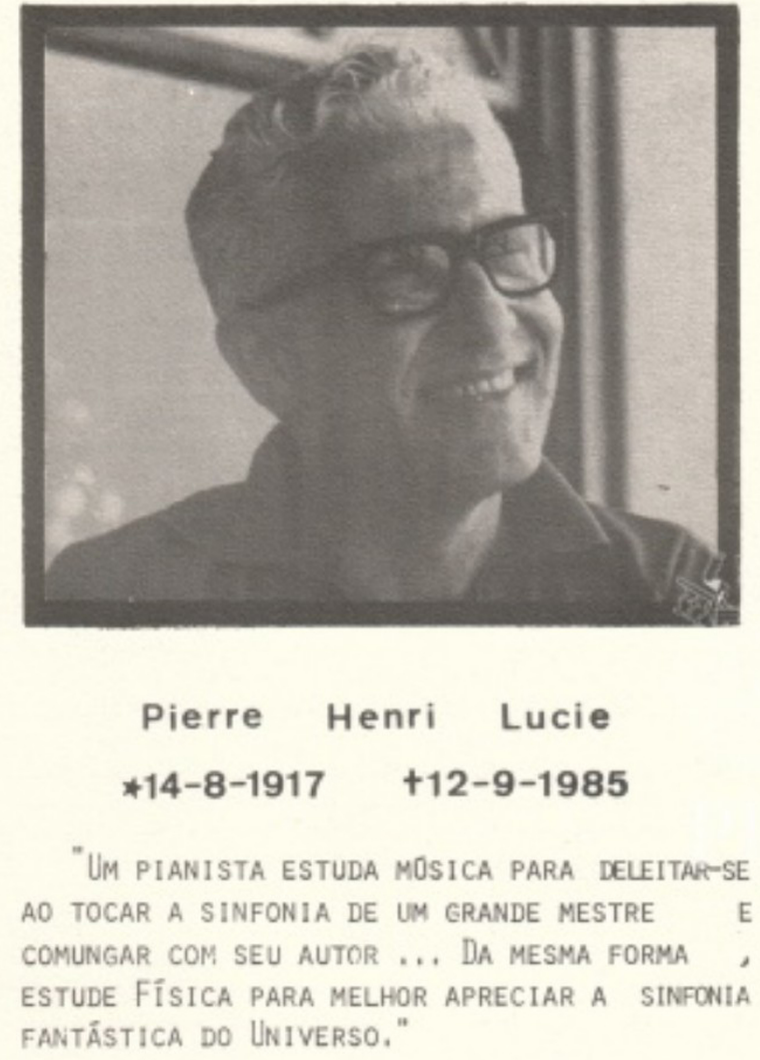

Fisica com Martins e Eu

Figura 11: Homenagem post-mortem ao Professor Pierre Lucie. Fonte: PUC-Rio.

que contribuíram para a sua formação. Uma pena que livros como este não sejam mais produzidos por ai.

Apesar de não ter conhecido o professor Lucie em vida, sinto-me privilegiado por conhecê-lo através deste trabalho. Sua história de vida e trajetória, saindo de uma situação desesperadora de uma Europa arrasada pela guerra para chegar ao Brasil com o sonho de uma vida melhor é inspiradora (figura 11).

Expresso ao final desse trabalho minha gratidão a Pierre Lucie por seu exemplo e trabalho, que juntamente com tantos outros bons professores, contribuíram para a melhoria do ensino da física em nosso país.

\section{Referências}

[1] Robert Locqueneux, Bouasse et L'esprit Taupin (BibNum Education, France, 2010).

[2] Regis de Moraes, Stress Existencial E Sentido Da Vida (Edições Loyola, São Paulo, 1997).

[3] Maurice Jacques Bazin, Revista Brasileira de Ensino de Física 7, 3 (1985).

[4] Susana de Souza Barros, Marcos Elia, Pierre Lucie: Professor e Educador de Cientistas (Editora UFRJ, Rio de Janeiro, 2010). 
[5] Sérgio Costa Ribeiro, in: Pierre Lucie: Professor e Educador de Cientistas, editado por Susana de Souza Barros e Marcos Elia (Editora UFRJ, Rio de Janeiro, 2010).

[6] Pierre Henri Lucie, Física com Martins e Eu: Introdução à Física, Cinemática (Raval Artes Gráficas LTDA, Rio de Janeiro, 1969), v. 1.

[7] Evaldo Victor Lima Bezerra, O Livro Didático de Pierre Lucie. Trabalho de Conclusão de Curso, Pontifícia Universidade Católica do Paraná, Curitiba, 2016.

[8] José Leonardo Demétrido de Souza, Tempo de Mudança: Atas XI Simpósio Nacional de Ensino de Física (Editora FCA, Niterói, 1995), p. 527-534.

[9] Roberto de Andrade Martins, "Física com Martins e Eu" por Pierre Lucie, com Ilustrações de Henfil, disponível em www. academia.edu/4811797, acesso em 11 dez. 2015.

[10] Brasil, Guia de Livros Didáticos: PNLD 2015 - Física Ensino Médio (Ministério da Educaão, Brasília, 2014).

[11] Pierre Henri Lucie, Física com Martins e Eu: Dinâmica da Partícula (Raval Artes Gráficas LTDA, Rio de Janeiro, 1970), v. 2

[12] Carlos Alberto Serpa de Oliveira, in: Pierre Lucie: Professor e Educador de Cientistas, editado por Susana de Souza Barros e Marcos Elia (Editora UFRJ, Rio de Janeiro, 2010), p. 53-56. 